\title{
Predictors of Extracapsular Extension in Patients With Squamous Cell Carcinoma of the Head and Neck and Outcome Analysis
}

Toms Vengaloor Thomas ${ }^{1}$, Madhava R. Kanakamedala ${ }^{2}$, Eldrin Bhanat ${ }^{3}$, Anu Abraham ${ }^{4}$, Eswar Mundra ${ }^{1}$, Ashley A. Albert ${ }^{1}$, Shankar Giri ${ }^{5}$, Rahul Bhandari ${ }^{5}$, Srinivasan Vijayakumar ${ }^{1}$

1. Radiation Oncology, University of Mississippi Medical Center, Jackson, USA 2. Radiation Oncology, Texas Oncology, Amarillo, USA 3. Orthopaedic Surgery, University of Mississippi Medical Center, Jackson, USA 4. Pathology, Universtiy of Mississippi Medical Center, Jackson, USA 5. Radiation Oncology, G.V. (Sonny) Montgomery VA Medical Center, Jackson, USA

Corresponding author: Toms Vengaloor Thomas, tvthomas@umc.edu

\section{Abstract}

\section{Introduction}

Extracapsular extension (ECE) in the lymph nodes for patients with head and neck cancer has been found to be a poor prognostic factor in multiple studies. The purpose of the study is to evaluate the predictive factors for ECE on computer tomography (CT) imaging for patients undergoing surgery and to analyze outcomes.

\section{Methods}

We conducted an Institutional Review Board-approved, Health Insurance Portability and Accountability Act (HIPAA)-compliant retrospective review of 82 patients with biopsy-proven squamous cell carcinomas of the head and neck who underwent definitive surgery without neoadjuvant chemotherapy or radiation therapy. CT scans were evaluated for the level of involvement, size, and presence or absence of central necrosis. Extracapsular extension in lymph nodes on the postoperative pathology was correlated with the central necrosis in the lymph nodes appreciated on the CT neck with contrast. Survival estimates were evaluated using the Kaplan-Meier test.

\section{Results}

ECE on postoperative pathology was seen in $74.07 \%$ of patients who had evidence of central necrosis in lymph nodes on preoperative CT neck compared to $46.43 \%$ without CT necrosis ( $\mathrm{p}=0.013$ ). The incidence of ECE is higher in poorly differentiated tumors and also nodal stages $>\mathrm{N} 2 \mathrm{c}$ at presentation. Patents with ECE had inferior disease-free and overall survival (OS).

\section{Conclusions}

Review began 02/28/2021 Review ended 07/20/2021 Published 07/28/2021

\section{() Copyright 2021}

Vengaloor Thomas et al. This is an open access article distributed under the terms of the Creative Commons Attribution License CC-BY 4.0., which permits unrestricted use, distribution, and reproduction in any medium, provided the original author and source are credited.
Our results reveal that patients with necrosis on CT and with moderately to poorly differentiated tumors have a high incidence of extracapsular extension. There was no difference in local control (LC) between the groups of patients, but the OS was inferior in patients with ECE. Predicting extracapsular extension upfront helps to formulate the appropriate treatment. We propose to study additional chemotherapy to improve outcomes in patients with positive extracapsular extension.

Categories: Pathology, Radiation Oncology, Oncology

Keywords: extracapsular extension, necrosis, head and neck cancer, outcomes, predicting ece, lymph node necrosis

\section{Introduction}

Peters et al. studied the criteria predicting the risk of local recurrence in the neck after surgery in patients with squamous cell carcinoma of the head and neck [1]. In their multivariate analysis, extracapsular extension (ECE) in lymph nodes was the single most important prognostic variable predicting treatment failure in the neck. In this randomized trial, the local control improved in the high-risk group with the addition of adjuvant radiation therapy escalating the dose to 63 Gray (Gy). Subsequent trials categorized those patients with extracapsular extension into the high-risk category.

Both the European organization for Research and Treatment of Cancer (EORTC) and the Radiation Therapy Oncology Group (RTOG) conducted randomized trials in which patients with high-risk features were randomized to either radiation therapy alone versus concurrent chemo-radiation therapy (CRT) $[2,3]$. Both these trials confirmed improvements in loco-regional controls with the addition of chemotherapy to radiation therapy in high-risk patients, even though the criteria for inclusion were not similar in these trials. A subsequent meta-analysis that combined RTOG and EORTC studies revealed that margin positivity and extracapsular involvement were the two factors that benefitted from adding chemotherapy to radiation 


\section{Cureus}

therapy [4].

As previously reported, ECE is highly correlated with the size of the lymph nodes, but nodes less than $1 \mathrm{~cm}$ may also harbor ECE at a rate as high as $25 \%[5,6]$. Several studies evaluated the utility of Computed Tomography (CT) scans in diagnosing the ECE, but these were with negatively reported results [7-13].

\section{Materials And Methods}

At the University of Mississippi Medical Center, we retrospectively evaluated 82 patients diagnosed with squamous cell carcinomas of the head and neck, treated between 2008 and 2014. Institutional review board approval was obtained for a retrospective review of these patients. Initial staging at diagnosis was performed utilizing CT neck with contrast. CT scans were also evaluated for the level of involvement, size, and presence or absence of central necrosis (Figure 1). All patients underwent surgical resection of primary cancer with neck dissection as a means of definitive treatment, without any neoadjuvant chemotherapy or radiation therapy. Extracapsular extension in lymph nodes on the postoperative pathology (Figures 2, 3) was correlated with the central necrosis in the lymph nodes appreciated on the CT neck with contrast. Patients were treated with either radiation therapy alone or concurrent CRT after the surgery, depending on the postoperative pathological risk factors.

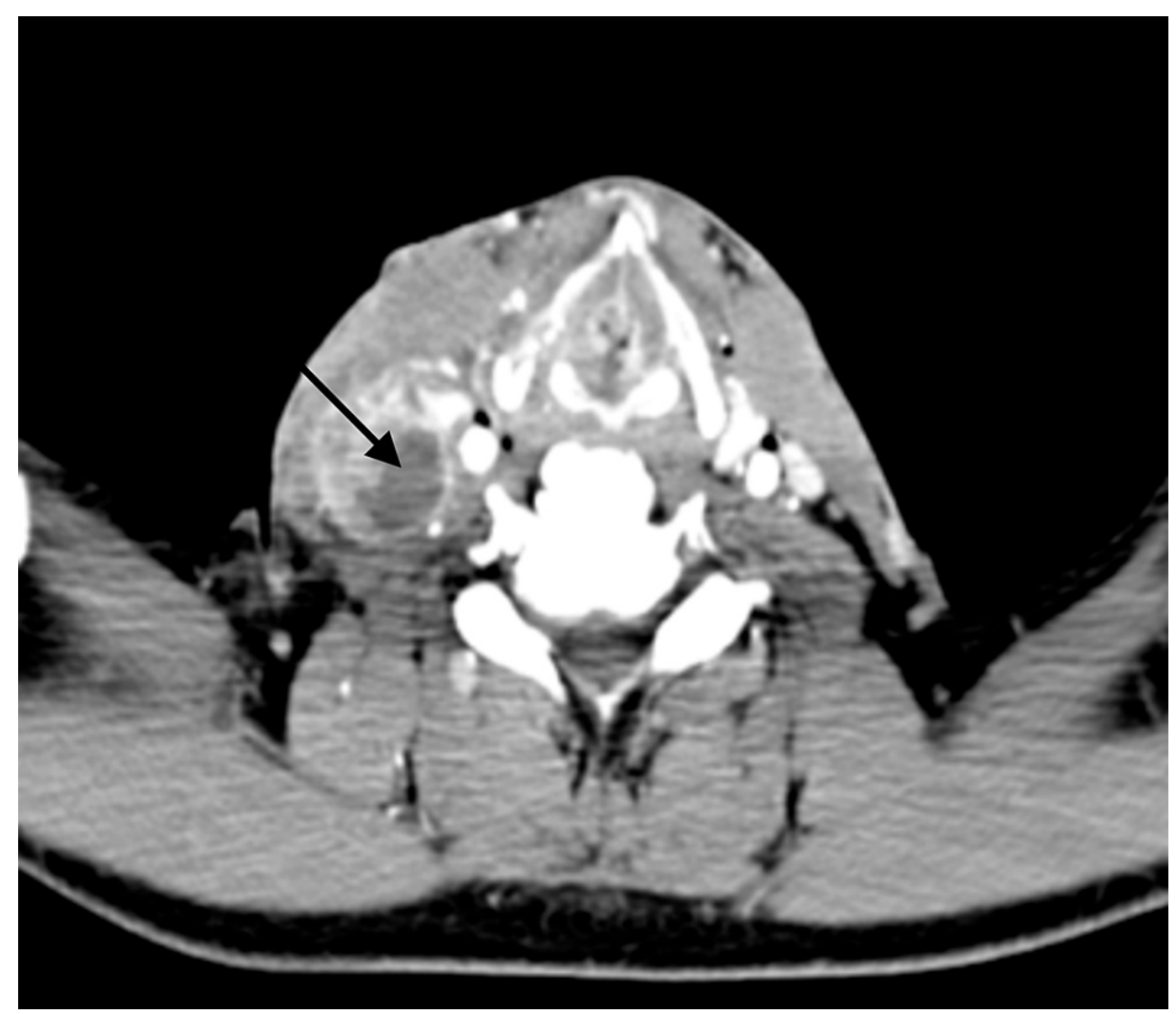

FIGURE 1: Computed tomography images of necrotic lymph nodes (necrotic lymph nodes in right level 3). Black arrow pointing towards the necrosis. 


\section{Cureus}

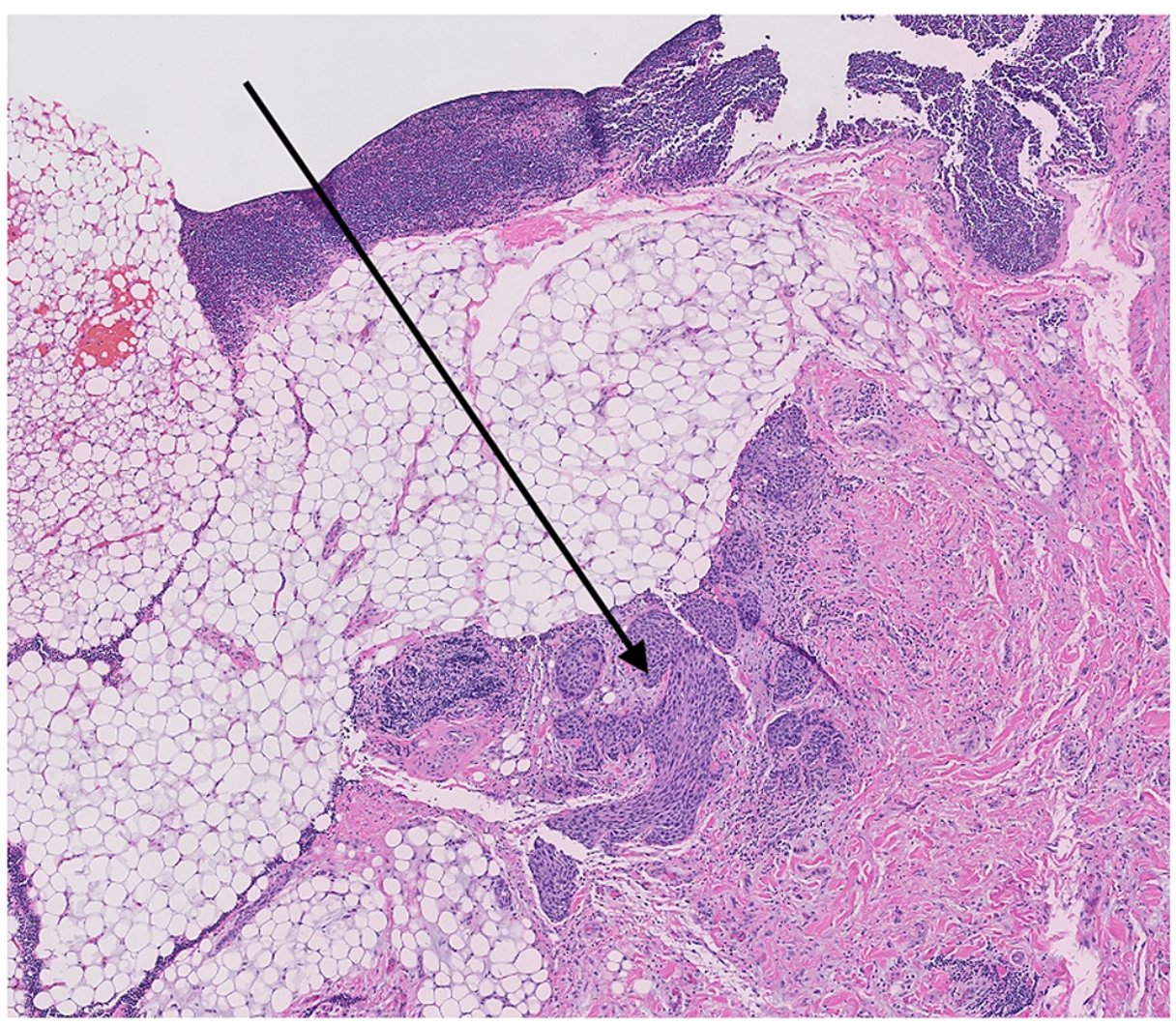

FIGURE 2: Extracapsular extension in lymph nodes on post-operative pathology (high power 10x).

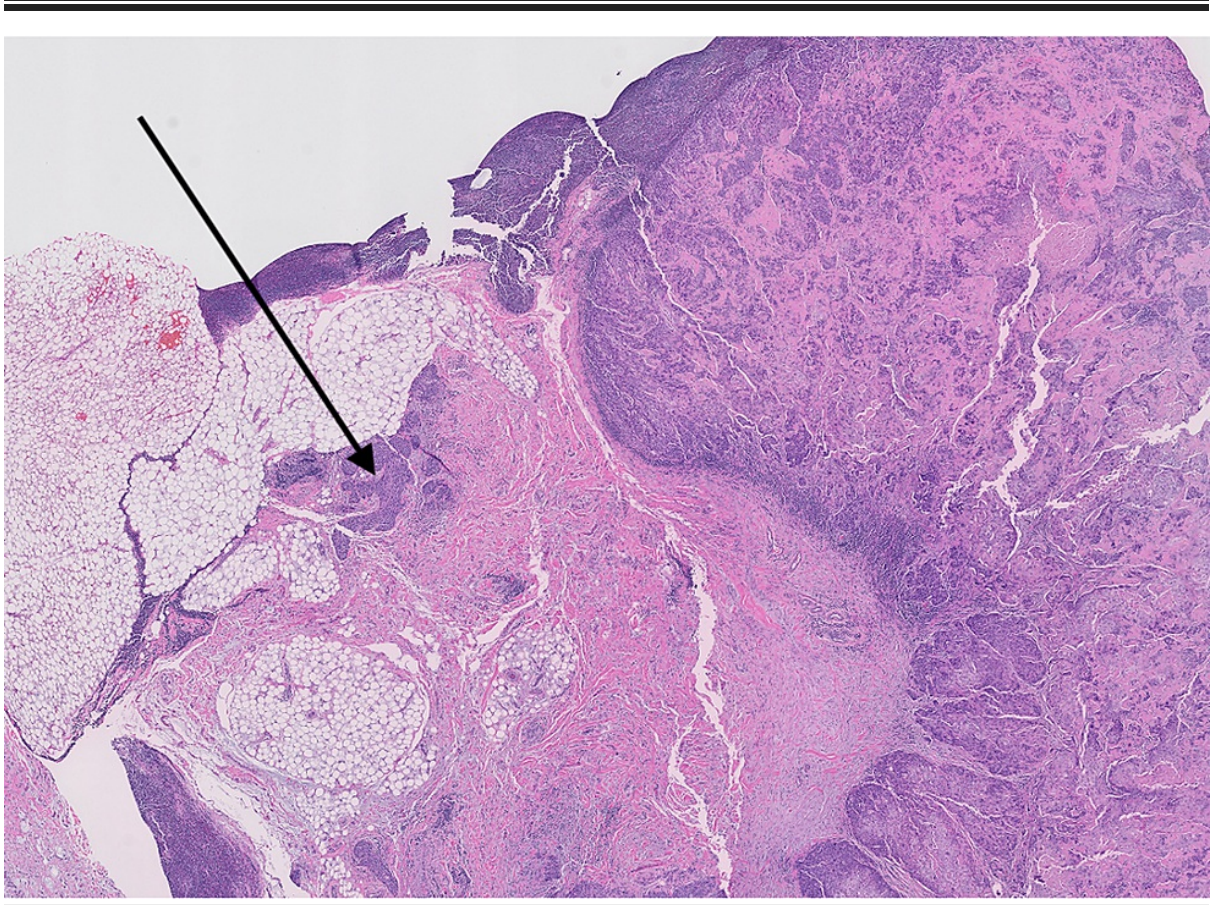

FIGURE 3: Extracapsular extension in lymph nodes on post-operative pathology (low power, 2x).

Radiotherapy was delivered utilizing Intensity Modulated Radiation Therapy/Volumetric Modulated Arc Therapy (IMRT/VMAT) techniques. After completing the adjuvant treatment, the patients were followed up per National Comprehensive Cancer Network (NCCN) guidelines. 


\section{Cureus}

SPSS Statistics version 23 (IBM Corp., Armonk, USA) was used for statistical analysis. The cross-associations between variables were tested using the cross tabs function. A Chi-Square test was used between categorical variables to justify and estimate the significance of the association. The survival estimates for overall survival, disease-free survival, and distant metastasis-free survival were evaluated using the Kaplan-Meier test. Logrank test was used to estimate the level of significance in these tests. Cox regression using backward elimination was used to determine the significant covariates in the calculation of survival.

\section{Results}

Of the 82 patients, 33 patients had an oral cavity primary, six with oropharynx, 30 with larynx, six with hypopharynx, six with skin, and one with an unknown primary. Based on the American Joint Committee on Cancer (AJCC) nodal staging 7th edition, 13 patients were grouped into N1, four patients into N2a, 25 patients into N2b, 35 patients into N2c, and five patients had N3 disease. The percentage of nodes with ECE based on the nodal stage was evaluated by substages (Table 1). ECE incidence increases with the N stage, with $20.73 \%$ positive ECE in N1+N2a, 60\% in N2b, $80 \%$ in N2c, and 100\% in N3 nodal disease.

\begin{tabular}{|c|c|c|}
\hline Nodal Stage & Number of patients (82) & ECE: Number (\%) \\
\hline $\mathrm{N} 1+\mathrm{N} 2 \mathrm{a}$ & $17 / 82$ & 7/17 (20.73\%) \\
\hline $\mathrm{N} 2 \mathrm{~b}$ & $25 / 82$ & $15 / 25(60 \%)$ \\
\hline N2c & $35 / 82$ & 28/35 (80\%) \\
\hline N3 & $5 / 82$ & $5 / 5(100 \%)$ \\
\hline \multicolumn{3}{|l|}{ Nodal Size } \\
\hline$<3 \mathrm{~cm}$ & 57 & 33/57 (57.90\%) \\
\hline$>3 \mathrm{~cm}$ & 25 & 20/25 (80\%) \\
\hline
\end{tabular}

\section{TABLE 1: Extracapsular extension (ECE) and its relation to nodal stage and nodal size.}

Overall, the median size of the nodes was $2.5 \mathrm{~cm}$ (range 0.3-6.5 cm). As can be seen in Table 1 , we analyzed the incidence of ECE based on nodal size. Prevalence of ECE in lymph nodes of size $<3 \mathrm{~cm}$ was $57.9 \%$, which proved to be worse with increasing nodal size. Specifically, there was an $80 \%$ prevalence of ECE in lymph nodes $>3 \mathrm{~cm}$

Among 82 patients, 54 were found to have central necrosis in lymph nodes on CT imaging performed for staging. We correlated the extracapsular extension in the histopathology reports to the necrosis on the CT scans. ECE was positive in $46.4 \%$ of patients without necrosis on CT, whereas ECE was positive in $74.07 \%$ of patients with necrotic lymph nodes and was statistically significant $(\mathrm{p}=0.013)$. We found a similar correlation between necrosis and ECE, even in lymph nodes size $<3 \mathrm{~cm}(\mathrm{n}=57)$, as shown in Table 2.

\begin{tabular}{|c|c|c|c|c|}
\hline \multirow[t]{3}{*}{ All Nodes $=82$ pts } & & ECE(+ve) & ECE(-ve) & p-value \\
\hline & Necrosis(-ve)=28 & $13 / 28(46.43 \%)$ & 15/28 (53.57\%) & \multirow{2}{*}{0.013} \\
\hline & Necrosis $(+v e)=54$ & 40/54 (74.07\%) & $14 / 54$ (25.93\%) & \\
\hline \multicolumn{5}{|c|}{ Nodes $<3 \mathrm{~cm}=57 \mathrm{pts}$} \\
\hline & Necrosis(-ve)=25 & $10 / 25(40.00 \%)$ & $15 / 25(60.00 \%)$ & \multirow{2}{*}{0.016} \\
\hline & Necrosis $(+v e)=32$ & 23/32 (71.88\%) & 9/32 (28.13\%) & \\
\hline
\end{tabular}

TABLE 2: Correlation of necrosis with extracapsular extension (ECE).

$\mathrm{ECE}(+\mathrm{ve})$ : extracapsular extension is present; $\mathrm{ECE}(-\mathrm{ve})$ : extracapsular extension is absent; Necrosis(+ve): necrosis is present on the CT scan in the lymph node; Necrosis(-ve): necrosis is absent in the lymph node on CT scan.

Among the 82 patients under evaluation, only three patients had well-differentiated tumors, while 59 were moderately differentiated, and 20 were poorly differentiated, as seen in Table 3 . The extracapsular extension 


\section{Cureus}

incidence was high in tumors that were poorly differentiated at around $80 \%$, resulting in no statistically significant difference in ECE positivity based on the presence or absence of necrosis in this histopathological group. However, among the moderately differentiated group, ECE was present in $38.4 \%$ of the lymph nodes without necrosis versus $74.29 \%$ in lymph nodes with necrosis. This finding shows a statistically significant increase in ECE in the moderately differentiated group with necrotic lymph nodes.

\begin{tabular}{|c|c|c|c|}
\hline Differentiation & & ECE(+ve) & p-value \\
\hline \multirow[t]{2}{*}{ Moderate $(N=59 / 82)$} & Necrosis $(-$ ve $)=24$ & $10 / 24(38.46 \%)$ & 0.012 \\
\hline & $\operatorname{Necrosis}(+\mathrm{ve})=35$ & 26/35 (74.29\%) & \\
\hline \multirow[t]{2}{*}{ Poorly (N-=20/82) } & Necrosis(-ve)=4 & $3 / 4(75.00 \%)$ & 0.531 \\
\hline & Necrosis(+ve)=16 & $14 / 16(87.50 \%)$ & \\
\hline
\end{tabular}

TABLE 3: Correlation of necrosis with extracapsular extension (ECE) as based on differentiation: moderately (G2) versus poorly (G3) differentiated.

ECE(+ve): extracapsular extension is present; Necrosis(+ve): necrosis is present on the CT scan in the lymph node; Necrosis(-ve): necrosis is absent in the lymph node on CT scan.

Besides, we evaluated endpoints, including loco-regional failure (LRF), distant metastases (DM), and overall survival (OS) in patients who completed all the prescribed adjuvant treatment. We excluded 13 patients that were non-compliant with the adjuvant treatment and follow-up visits. Thus, a total of 69 patients were available in the final analysis.

The median follow-up was five years. The loco-regional failures were similar in both groups ( $16 \mathrm{vs.} 17.7 \%$, $\mathrm{p}=0.811$ ). However, the distant failures (Figure 4 ) were much higher in the ECE+ve group of $34.4 \%$, whereas it was only $8.5 \%$ in the ECE-ve group $(\mathrm{p}=0.035)$. We observed a statistically significant decline in disease-free survival (DFS) (Figure 5) in the ECE+ve group compared to ECE-ve ( $49.5 \%$ vs. $76.2 \%, \mathrm{p}=0.048$ ), translating to decrement in the OS (59.4\% in ECE+ve vs. $88.2 \%$ in ECE-ve, $\mathrm{p}=0.02$ ) (Figure ). Table 4 summarizes the outcomes. 


\section{Cureus}

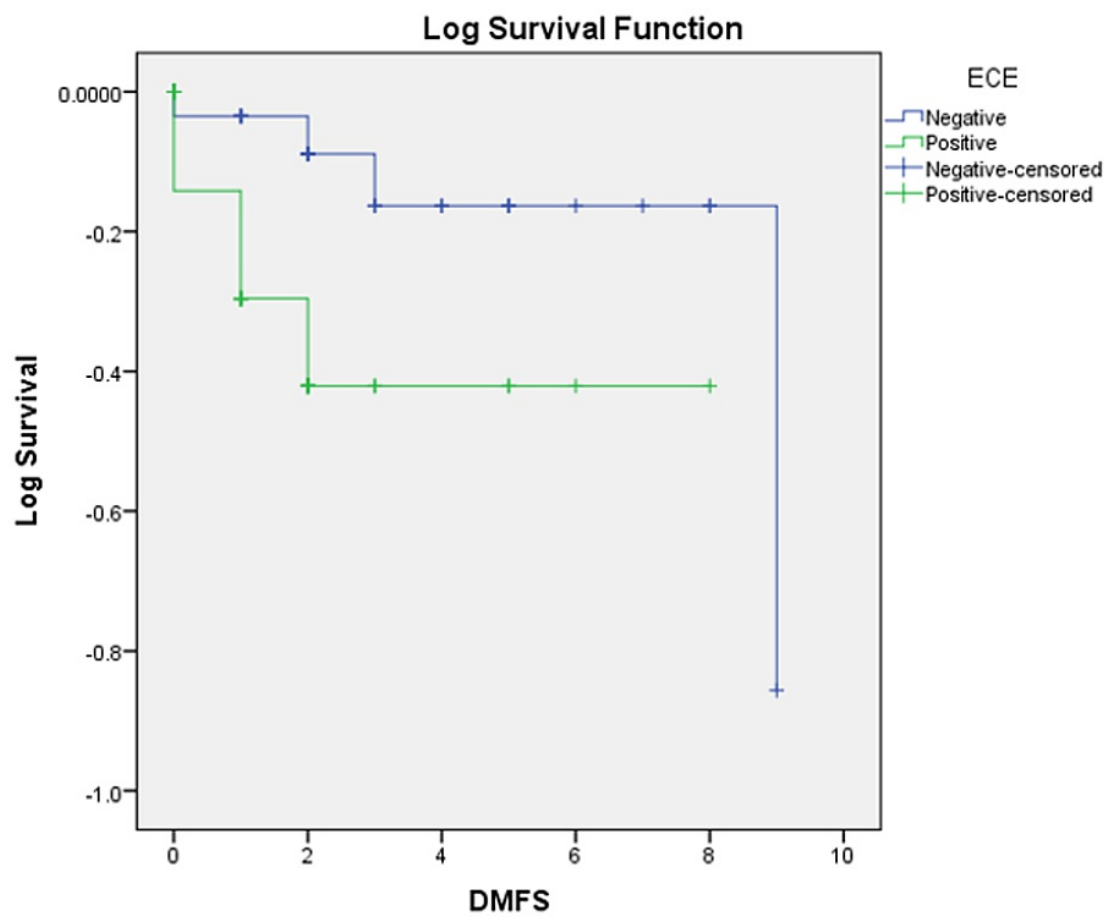

FIGURE 4: Kaplan-Meier distant metastasis-free survival (DMFS) curve for patients based on the presence (ECE+ve) or absence (ECE-ve) of extracapsular extension (ECE) of lymph nodes for head and neck cancer patients.

ECE+ve: extracapsular extension present; ECE-ve: extracapsular extension absent. 


\section{Cureus}

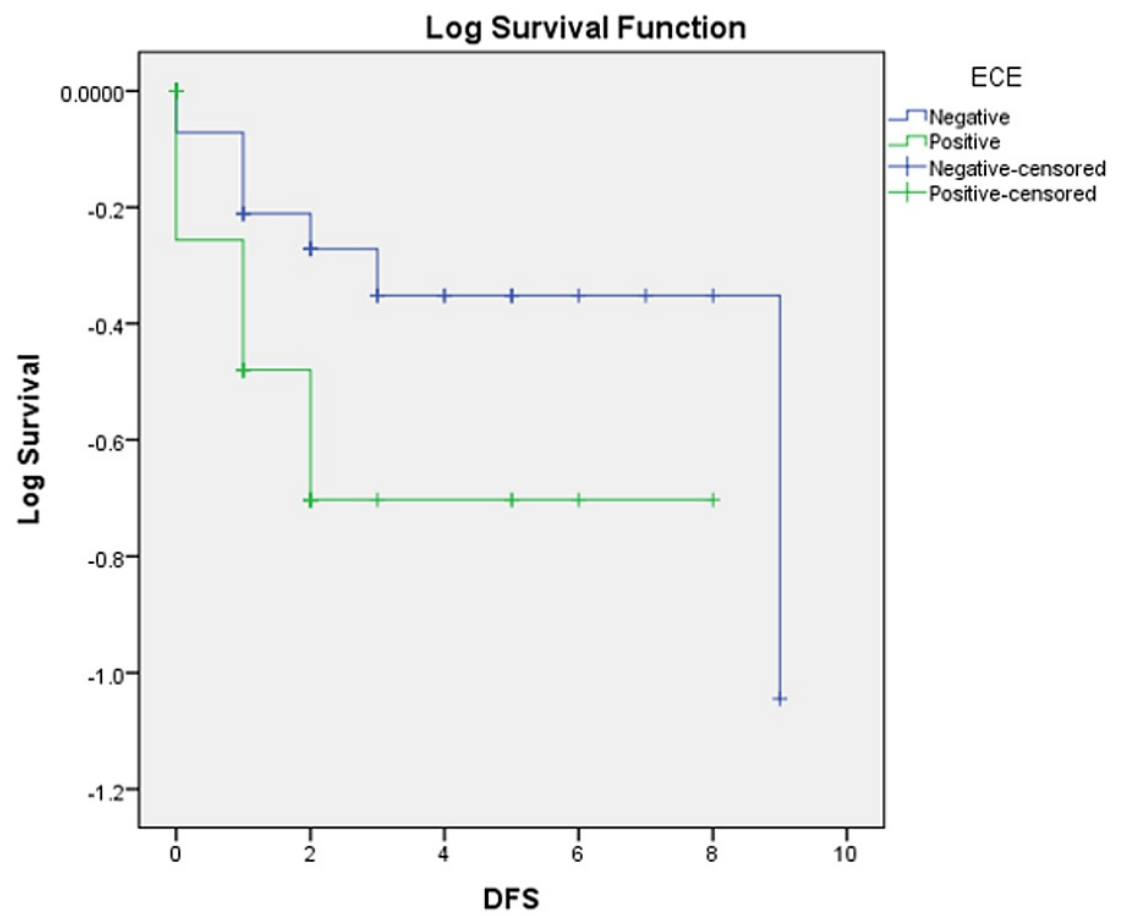

FIGURE 5: Kaplan- Meier disease-free survival (DFS) curve based on the presence (ECE+ve) or absence (ECE-ve) of extracapsular extension (EXE) of lymph nodes for head and neck cancer patients.

ECE+ve: extracapsular extension present; ECE-ve: extracapsular extension absent. 


\section{Cureus}

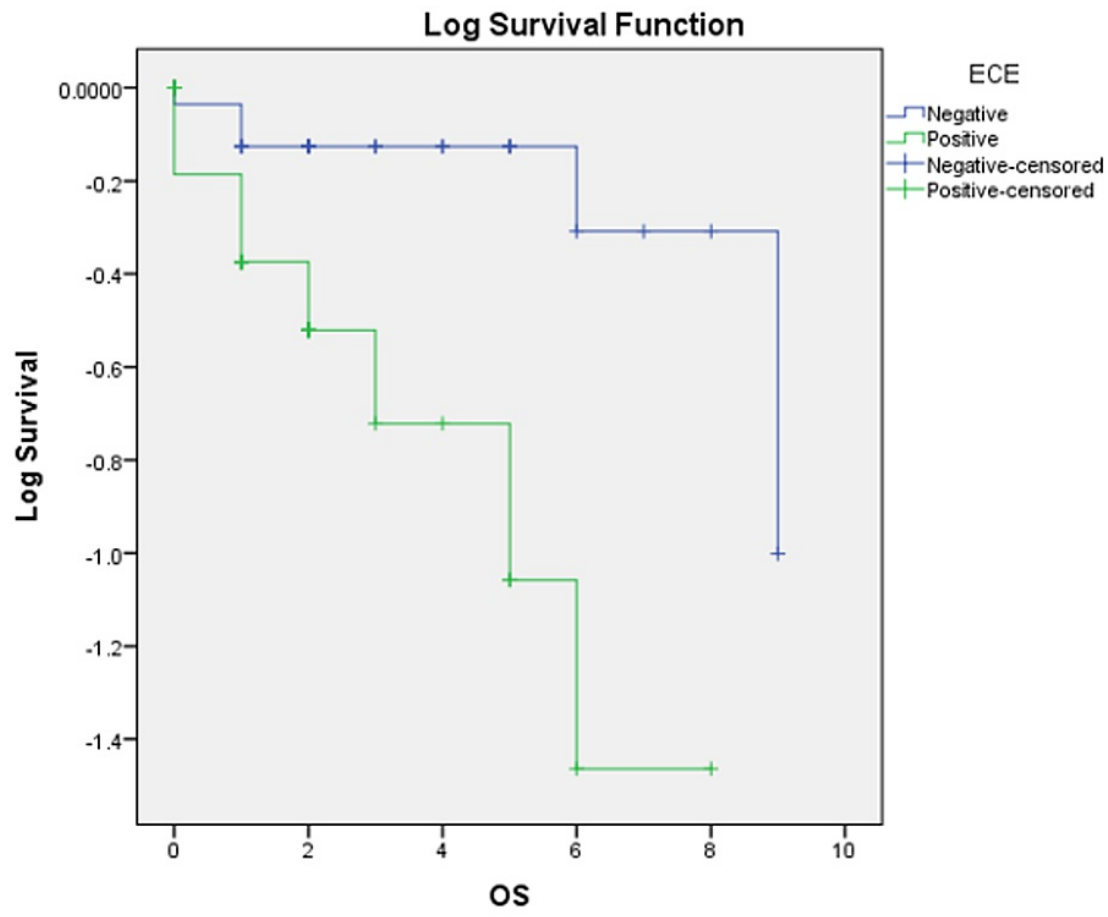

FIGURE 6: Kaplan-Meier overall survival (OS) curve based on the presence $(E C E+v e)$ or absence (ECE-ve) of extracapsular extension (ECE) of lymph nodes for head and neck cancer patients.

$\mathrm{ECE}+\mathrm{ve}$ : extracapsular extension present; ECE-ve: extracapsular extension absent.

\begin{tabular}{|c|c|c|c|}
\hline Outcomes & ECE(-ve) & ECE(+ve) & P-value \\
\hline Loco Regional Failure & $16 \%$ & $17.7 \%$ & 0.811 \\
\hline Distant Failure & $8.5 \%$ & $34.4 \%$ & 0.035 \\
\hline Disease-Free Survival & $76.2 \%$ & $49.5 \%$ & 0.048 \\
\hline Overall Survival & $88.2 \%$ & $59.4 \%$ & 0.02 \\
\hline
\end{tabular}

TABLE 4: Outcome analysis based on extracapsular extension (ECE).

ECE+ve: extracapsular extension present; ECE-ve: extracapsular extension absent.

\section{Discussion}

Necrosis can be defined as cell death caused by loss of membrane integrity, intracellular organelle swelling, and adenosine triphosphate (ATP) depletion leading to an influx of calcium. Necrosis involves rapid and passive cell death. Necrosis is associated with the loss of plasma membrane integrity, swelling, and bursting of groups of cells rather than single cells at the cellular level. Necrosis is typically attributed to tumors with aggressive biology, as they have been found to outgrow their blood supply quickly [14]. Generally, there is an increased demand for nutrients and oxygen in the tumor microenvironment. Tumor hypoxia and depletion of energy in tumors create an acidic environment that leads to extrinsic activation of immune cells to release cytotoxins, which results in necrosis and paradoxically enhanced tumor growth [15]. The ability of nodal metastases to recruit degradation factors that permit the tumor to break through the lymph node capsule represents a very aggressive tumor biology $[16,17]$.

In our study, we found a statistically significant correlation between necrosis in lymph nodes on CT and the presence of extracapsular extension on postoperative pathology (74\% vs. $46 \%$ for lymph nodes with and without necrosis, respectively). This finding was true even in smaller lymph nodes, size $<3 \mathrm{~cm}$. This 
retrospective review confirms the results from earlier studies that necrosis correlates with ECE in a larger patient population $[18,19]$.

When the data is further analyzed based on differentiation, a significant correlation was observed in patients with moderate differentiation (74\% vs. $38 \%$ for lymph nodes with and without necrosis on lymph nodes, respectively), but not in poorly differentiated histology patients. However, ECE incidence was high in poorly differentiated (82.6\%) compared to moderately differentiated histology (53.4\%). This finding proves that poorly differentiated histology itself denotes aggressive tumor biology, thus increasing the risk of ECE with or without central necrosis on the preoperative imaging.

More than $80 \%$ of patients with neck nodal stage $>$ N2c, poorly differentiated histology, and nodal size $>3 \mathrm{~cm}$ had ECE. Predicting extracapsular extension becomes valuable information for clinicians planning treatment [20-23]. Therefore, in patients who are at high risk for having an extracapsular extension of tumor in the lymph nodes, it is better to be treated with definitive CRT rather than the combined modality of surgery followed by adjuvant CRT. We acknowledge that the American Joint Committee on Cancer (AJCC) 8th edition staging system has incorporated ECE into the staging system [24].

\section{Conclusions}

Our results reveal that patients with necrosis on CT and with moderately to poorly differentiated tumors have a high incidence of extracapsular extension. There was no difference in local control (LC) between the groups of patients, but the OS was inferior in patients with ECE, which can be explained by the higher incidence of distant metastases in this group. As the development of distant metastases was higher in patients with ECE, we propose to study administering additional chemotherapy in this group of patients to prevent distant metastases and improve overall survival.

\section{Additional Information \\ Disclosures}

Human subjects: Consent was obtained or waived by all participants in this study. University of Mississippi Medical Center issued approval DHHS FWA \#00003630 IORG \#0000043 IRB 1 Registration \#00000061 IRB 2 Registration \#00005033. IRB File \#2010-0252 Outcomes following treatment for Head and Neck Cancer Your Amendment was reviewed and approved by the Expedited Review process on 11/11/2019. You may implement the amendment. Animal subjects: All authors have confirmed that this study did not involve animal subjects or tissue. Conflicts of interest: In compliance with the ICMJE uniform disclosure form, all authors declare the following: Payment/services info: All authors have declared that no financial support was received from any organization for the submitted work. Financial relationships: All authors have declared that they have no financial relationships at present or within the previous three years with any organizations that might have an interest in the submitted work. Other relationships: All authors have declared that there are no other relationships or activities that could appear to have influenced the submitted work.

\section{References}

1. Peters LJ, Goepfert H, Ang KK, et al.: Evaluation of the dose for postoperative radiation therapy of head and neck cancer: first report of a prospective randomized trial. Int J Radiat Oncol Biol Phys. 1993, 26:3-11. 10.1016/0360-3016(93)90167-t

2. Bernier J, Domenge C, Ozsahin M, et al.: Postoperative irradiation with or without concomitant chemotherapy for locally advanced head and neck cancer. N Engl J Med. 2004, 350:1945-52. 10.1056/NEJMoa032641

3. Cooper JS, Pajak TF, Forastiere AA, et al.: Postoperative concurrent radiotherapy and chemotherapy for high-risk squamous-cell carcinoma of the head and neck. N Engl J Med. 2004, 350:1937-44. 10.1056/NEJMoa032646

4. Bernier J, Cooper JS, Pajak TF, et al.: Defining risk levels in locally advanced head and neck cancers: a comparative analysis of concurrent postoperative radiation plus chemotherapy trials of the EORTC (\#22931) and RTOG (\# 9501). Head Neck. 2005, 27:843-50. 10.1002/hed.20279

5. Don DM, Anzai Y, Lufkin RB, Fu YS, Calcaterra TC: Evaluation of cervical lymph node metastases in squamous cell carcinoma of the head and neck. Laryngoscope. 1995, 105:669-74. 10.1288/00005537199507000-00001

6. Giancarlo T, Palmieri A, Giacomarra V, Russolo M: Pre-operative evaluation of cervical adenopathies in tumours of the upper aerodigestive tract. Anticancer Res. 1998, 18:2805-9.

7. Souter MA, Allison RS, Clarkson JH, Cowan IA, Coates MH, Wells JE: Sensitivity and specificity of computed tomography for detection of extranodal spread from metastatic head and neck squamous cell carcinoma. J Laryngol Otol. 2009, 123:778-82. 10.1017/S0022215109004332

8. Url C, Schartinger VH, Riechelmann H, Glückert R, Maier H, Trumpp M, Widmann G: Radiological detection of extracapsular spread in head and neck squamous cell carcinoma (HNSCC) cervical metastases. Eur J Radiol. 2013, 82:1783-7. 10.1016/j.ejrad.2013.04.024

9. Maxwell JH, Rath TJ, Byrd JK, et al.: Accuracy of computed tomography to predict extracapsular spread in p16-positive squamous cell carcinoma. Laryngoscope. 2015, 125:1613-8. 10.1002/lary.25140

10. Steinkamp HJ, van der Hoeck E, Böck JC, Felix R: [The extracapsular spread of cervical lymph node 
metastases: the diagnostic value of computed tomography]. Rofo. 1999, 170:457-62. 10.1055/s-20071011073

11. Aiken AH, Poliashenko S, Beitler JJ, et al.: Accuracy of preoperative imaging in detecting nodal extracapsular spread in oral cavity squamous cell carcinoma. AJNR Am J Neuroradiol. 2015, 36:1776-81. 10.3174/ajnr.A4372

12. Su Z, Duan Z, Pan W, Wu C, Jia Y, Han B, Li C: Predicting extracapsular spread of head and neck cancers using different imaging techniques: a systematic review and meta-analysis. Int J Oral Maxillofac Surg. 2016, 45:413-21. 10.1016/j.ijom.2015.11.021

13. Oztürk C, Saraydarğolu O, Erişen L, Coşkun H, Basut O, Kasapoğlu F: The relationship between lymph node size and metastasis and extracapsular spread in squamous cell carcinoma of the larynx, orohypopharynx, and oral cavity. Kulak Burun Bogaz Ihtis Derg. 2008, 18:7-13.

14. Thomlinson RH, Gray LH: The histological structure of some human lung cancers and the possible implications for radiotherapy. Br J Cancer. 1955, 9:539-49. 10.1038/bjc.1955.55

15. Vakkila J, Lotze MT: Inflammation and necrosis promote tumour growth. Nat Rev Immunol. 2004, 4:641-8. 10.1038/nri1415

16. Johnson JT, Barnes EL, Myers EN, Schramm VL Jr, Borochovitz D, Sigler BA: The extracapsular spread of tumors in cervical node metastasis. Arch Otolaryngol. 1981, 107:725-9. 10.1001/archotol.1981.00790480001001

17. Alvi A, Johnson JT: Extracapsular spread in the clinically negative neck (N0): implications and outcome . Otolaryngol Head Neck Surg. 1996, 114:65-70.

18. Zoumalan RA, Kleinberger AJ, Morris LG, Ranade A, Yee H, DeLacure MD, Myssiorek D: Lymph node central necrosis on computed tomography as predictor of extracapsular spread in metastatic head and neck squamous cell carcinoma: pilot study. J Laryngol Otol. 2010, 124:1284-8. 10.1017/S0022215110001453

19. Randall DR, Lysack JT, Hudon ME, et al.: Diagnostic utility of central node necrosis in predicting extracapsular spread among oral cavity squamous cell carcinoma. Head Neck. 2015, 37:92-6. 10.1002/hed.23562

20. de Juan J, García J, López M, Orús C, Esteller E, Quer M, León X: Inclusion of extracapsular spread in the pTNM classification system: a proposal for patients with head and neck carcinoma. JAMA Otolaryngol Head Neck Surg. 2013, 139:483-8. 10.1001/jamaoto.2013.2666

21. Luchini C, Veronese N: The importance of extranodal extension in metastatic head and neck squamous cell carcinoma, in the light of the new AJCC cancer staging system. Oral Oncol. 2017, 66:e1-2. 10.1016/j.oraloncology.2016.12.032

22. Lewis JS Jr, Carpenter DH, Thorstad WL, Zhang Q, Haughey BH: Extracapsular extension is a poor predictor of disease recurrence in surgically treated oropharyngeal squamous cell carcinoma. Mod Pathol. 2011, 24:1413-20. 10.1038/modpathol.2011.105

23. Myers JN, Greenberg JS, Mo V, Roberts D: Extracapsular spread: a significant predictor of treatment failure in patients with squamous cell carcinoma of the tongue. Cancer. 2001, 92:12-3030. 10.1002/10970142(20011215)92:12<3030::aid-cncr10148>3.0.c0;2-p

24. Minion LE, Tewari KS: Cervical cancer - state of the science: from angiogenesis blockade to checkpoint inhibition. Gynecol Oncol. 2018, 148:609-21. 10.1016/j.ygyno.2018.01.009 